\title{
Erratum to: A note on stokes production of turbulence kinetic energy in the oceanic mixed layer: observations in the Baltic Sea
}

\author{
Lakshmi Kantha • Hans Ulrich Lass • Hartmut Prandke
}

Published online: 30 March 2010

(C) Springer-Verlag 2010

\section{Erratum to: Ocean Dynamics}

DOI 10.1007/s10236-009-0257-7

The original version of this article unfortunately contained a mistake.

The first sentence of the first paragraph under " 4 . The results" section on page 177 of the article should read:

Figure 3 shows the time series of the wind stress components $\tau_{x}, \tau_{y}$, friction velocity $\mathrm{u}_{*}$, the surface Stokes drift speed $\left|\vec{U}_{S}\right|, \overline{\eta^{2}}$ and the Langmuir number La defined as $L a=\left[\frac{(\vec{\tau} / \rho) \cdot \vec{U}_{S}}{u_{*}^{3}}\right]^{1 / 3}=\left[\frac{u_{*}^{2} \mid \vec{U}_{S}}{u_{*}^{3}}\right]^{1 / 3}=\left[\frac{\left|\vec{U}_{S}\right|}{u_{*}^{*}}\right]^{1 / 3}$ since $\vec{\tau}$ and $\vec{U}_{S}$ are in the same direction. Note that this is a better way to define La than is the current practice since the larger the Langmuir number, the larger the Stokes production of TKE.

Responsible Editor: Richard John Greatbatch

The online version of the original article can be found under doi:10.1007/s10236-009-0257-7.

L. Kantha $(\bowtie)$

Department of Aerospace Engineering Sciences,

University of Colorado,

Boulder, CO, USA

e-mail: kantha@colorado.edu

H. U. Lass

Baltic Sea Research Institute,

Warnemunde,

Rostock, Germany

H. Prandke

ISW Wassermesstechnik,

Petersdorf, Germany 